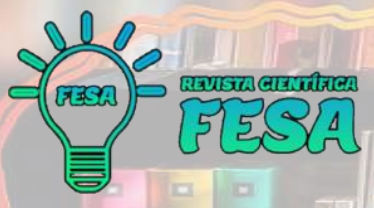

\title{
SOBREVIVÊNCIA E PRIMEIROS SOCORROS: CONCEITOS, DE- FINIÇÕES, CONSTRUCTOS E EXEMPLIFICAÇÕES PRÁTICAS
}

\author{
Denilson Carneiro de Lima ${ }^{1}$
}

\section{RESUMO}

Discorrer sobre o salvamento e a sobrevivência visa trazer as primeiras noções referentes a esses dois objetos, fornecendo conceitos, definições diversas, constructos e exemplificações práticas que serão direcionadas às ações em terra sejam elas com a meta de resgate, sejam de resolução própria. Dessa maneira, este artigo objetiva precipuamente fornecer subsídios necessários para aprimorar habilidades referentes à sobrevivência e aos primeiros socorros a estudantes e futuros profissionais que necessitem desses aprofundamentos para aprimorarem suas práticas laborais pertencentes a diversas áreas do conhecimento. De modo secundário, busca-se identificar os primeiros conceitos sobre salvamento e sobrevivência; reconhecer a importância dos cuidados com a saúde; interpretar a simbologia e a sinalização de socorro e distinguir as formas e tipos de abrigos. Portanto, é importante saber que a capacidade de sobrevivência residirá, amplamente, numa atitude mental adequada para enfrentar situações de emergência e na posse de estabilidade emocional, a despeito de sofrimentos físicos decorrentes da fadiga, da fome, da sede e de ferimentos, por vezes graves.

Palavras-chave: Sobrevivência; Primeiros Socorros; Salvamento; Situações de Emergência.

\section{ABSTRACT}

To discuss the rescue and survival aims to bring the first indications related to these two objects, providing concepts, diverse definitions, constructs and practical examples that will be directed to actions on the ground whether they with the goal of rescue, or of their own resolution. Thus, this article aims to provide necessary subsidies to improve skills related to survival and first aid to students and future professionals who need these deepening scans to improve their work practices belonging to various areas of knowledge. In a secondary way, we seek to identify the first concepts about rescue and survival; recognize the importance of health care; interpret symbology and relief signaling and distinguish the forms and types of shelters. Therefore, it is important to know that the ability to survive will largely reside in an adequate mental attitude to face emergency situations and in the possession of emotional stability, despite physical suffering stemming from fatigue, hunger, home and sometimes serious injuries.

Keywords: Survival; First aid; Salvage; Emergency situations.

\section{RESUMEM}

Para discutir el rescate y la supervivencia se pretende aportar las primeras indicaciones relacionadas con estos dos objetos, aportando conceptos, definiciones diversas, constructos y ejemplos prácticos que se dirigirán a acciones sobre el terreno ya sea con el objetivo de rescate, o de su

\footnotetext{
1 Possui graduação em Educação Física pela Universidade Castelo Branco (1999), Pós-graduação em Treinamento Desportivo pela Universidade Gama Filho (2008), Pós-graduando em Docência para o Ensino Superior IBMR, Aluno Especial do Programa de Pós-Graduação Stricto Sensu em Ciências do Exercício e do Esporte da UERJ (PPGCEE). Professor responsável pelas Capacitações em Suporte Básico de Vida -Cref1 em toda Região do Lagos.
} 
propia resolución. Así, este artículo pretende proporcionar las subvenciones necesarias para mejorar las competencias relacionadas con la supervivencia y los primeros auxilios a los estudiantes y futuros profesionales que necesiten de estos escaneos de profundización para mejorar sus prácticas laborales pertenecientes a diversas áreas del conocimiento. De manera secundaria, buscamos identificar los primeros conceptos sobre rescate y supervivencia; reconocer la importancia de la atención de la salud; interpretar la simbología y la señalización en relieve y distinguir las formas y tipos de refugios. Por lo tanto, es importante saber que la capacidad de supervivencia residirá en gran medida en una actitud mental adecuada para enfrentar situaciones de emergencia y en posesión de estabilidad emocional, a pesar del sufrimiento físico derivado de la fatiga, el hambre, el hogar y, a veces, lesiones graves.

Palabras clave: Supervivencia. Primeros auxilios. Salvamento. Situaciones de emergencia.

\section{INTRODUÇÃO}

Não é novidade que as mídias noticiem recorrentemente situações em que os seres humanos necessitaram de algum tipo de salvamento, geralmente envolvendo resgate, por profissionais regularmente credenciados para essa ação. Um exemplo ocorreu em Curitiba durante o mês de maio em 2021, quando um jovem de 26 anos foi resgatado de helicóptero depois de cair de um paredão enquanto descia o Morro do Anhangava, em Quatro Barras, na Região Metropolitana de Curitiba. Neste caso, a operação foi realizada via aérea por profissionais da Polícia Militar. Por ter sofrido ferimentos severos, escoriações e contusões nos braços e nas pernas, além de suspeita de trauma raquimedular, seria relativamente complicado para que o próprio trilheiro se salvasse sozinho.

Outra situação que envolveu salvamento foi a do piloto que, após 38 dias de desaparecimento, localizou um grupo de castanheiros que o ajudaram a contatar sua família. O homem havia partido de Alenquer em seu avião, acabou perdido no meio de uma mata fechada, onde ficou sozinho. O piloto declarou que se alimentou de frutas e ovos de aves durante o período em que esteve perdido. Esse instinto de sobrevivência foi o diferencial para a manutenção da vida do profissional aéreo que, ao contrário do exemplo anterior, foi o principal responsável pelo seu salvamento.

Outro caso comum de salvamento que pertence de igual forma ao imaginário infantil foi a da gata Mia, que subir em um telhado e não conseguiu descer. Após reiteradas tentativas de resgate por parte dos donos do animal, os bombeiros do $1^{\circ}$ Batalhão de Vitória foram chamados para resgatar o animal que agora se encontra em segurança junto à sua dona. Um fato assim estende a relevância 

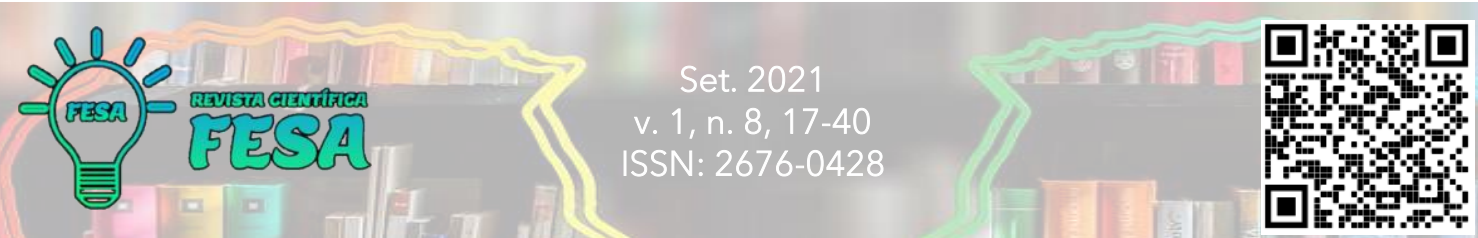

das técnicas de salvamento para todos os seres vivos, sejam eles humanos ou não.

Cabe destacar, ainda, que, em caso de desastres aéreos, os destroços das aeronaves podem servir como um recurso adequado de proteção se houver condições para esse fim. Um famoso caso foi o do ator e apresentador de TV Danton Mello que desapareceu no monte Roraima, em 1998, quando estava a caminho da montanha, na fronteira com a Venezuela, para realizar uma reportagem. Como estava num local de difícil acesso, foram mais de 30 horas, utilizando o abrigo improvisado, até a chegada do resgate. A aeronave só foi localizada após a descoberta feita por um indígena, que viu os destroços e avisou um posto da Funai. Mello e a equipe de TV foram encontrados por um helicóptero que participava das buscas e aguardava socorro em meio aos destroços.

Os abrigos que podem servir de aparato protetivo humano em situações de dificuldade, geralmente, ocorridas em terra e, em específico, em mata. Importante citar que essa proteção pode ampliar as chances de sobrevivência por fornecer uma proteção maior para o frio, sol, vento, chuva e para outro qualquer tipo de intempérie que possa surgir como a interferência de animais de grande porte ou não, como os insetos e outros vetores.

Antes de nos aprofundarmos nos tipos de abrigos, cabe destacar que estes devem servir como um aparato provisório e emergencial, sendo sempre priorizado o resgate o quanto antes. Não há a intenção de se construir edículas permanentes, mas somente um espaço adequado para o suporte à vida.

Somado a esse afã por sobreviver, grande parte das pessoas só se preocupam com a saúde depois que algo de ruim acontece, ações preventivas e hábitos saudáveis podem garantir uma maior sobrevivência humana. Os cuidados com saúde podem ser o diferencial para o aumento da expectativa de vida e, ainda, facilitar o atendimento, quando necessário, dos profissionais de saúde e de resgate.

O corpo humano deve ser considerado o bem maior de uma pessoa, já que é ele que o acompanha do início da vida até o final dela. Os bens materiais podem ser trocados ou descartados, mas encontrar peças de reposição, como por meio dos transplantes, por exemplo, para a estrutura corporal humana é possível, mas muito complexo e nem sempre totalmente adequado. 

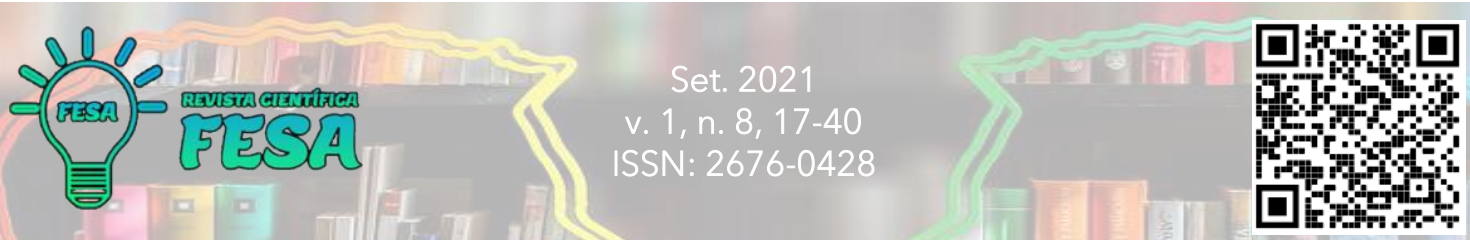

Situações como o fumo ou ingerir bebidas em demasia podem ocasionar lesões nos pulmões e no fígado de formas irreversíveis, reduzindo a expectativa de vida e podendo levar à morte precoce. Outros maus hábitos costumam passar despercebido e envolvem a seleção alimentar pobre e inadequada e, essencialmente, artificial. A ingestão de alimentos frescos pode ser o diferencial quando os indivíduos se deparam com situações que a vontade de sobreviver é colocada à prova, já que os organismos que recebem nutrientes provenientes de frutas $\mathrm{e}$ de vegetais apresentam uma resposta imune melhor do que os demais.

Portanto, falar de sobrevivência envolve diversos fatores. Por esse motivo, o presente artigo divide-se em Primeiros conceitos sobre salvamento e sobrevivência; Cuidados com a saúde; Simbologia e sinalização de socorro; Abrigos: formas e tipos.

\section{PRIMEIROS CONCEITOS SOBRE SALVAMENTO E SOBREVIVÊNCIA}

Seguindo a definição do dicionário virtual Michaelis (2021), o vocábulo salvamento significa ação ou efeito de salvar(-se); salvação; e local seguro que não oferece perigo. Dada a simplicidade de compreensão, há de se pensar, de modo equivocado, na possibilidade de se ter a mesma facilidade na sua execução.

Sua percepção está presente em diversos momentos da história, tendo como os primeiros registros as primeiras formações de salvamento, formalmente constituídos, no mundo foram criados pelo Imperador Augusto, cerca de 63 a.C a 14 d.C. A iniciativa era composta por sete cortes de seiscentos homens, conhecidas por "Armadas Romanas", às quais eram outorgadas recompensas pelos atos de salvamento de cidadãos que eram extensivas aos pais dos salvadores por terem procriado tais crianças. Após dois séculos, em 1914, surgiram as primeiras tentativas registradas para humanizar o conhecimento de salvar vidas no Brasil (SOBRASA, 2016).

Nota-se que a história da preservação humana tem seus primeiros passos com a origem do próprio homem sobre a Terra na percepção recorrente do desejo de sobreviver que possibilitou a criação de diversos meios de preservar a vida. O processo que levou o homem a entender como e por que prevenir e ajudar a outros de sua espécie durou milhares de anos (CBMSC, 2017). 

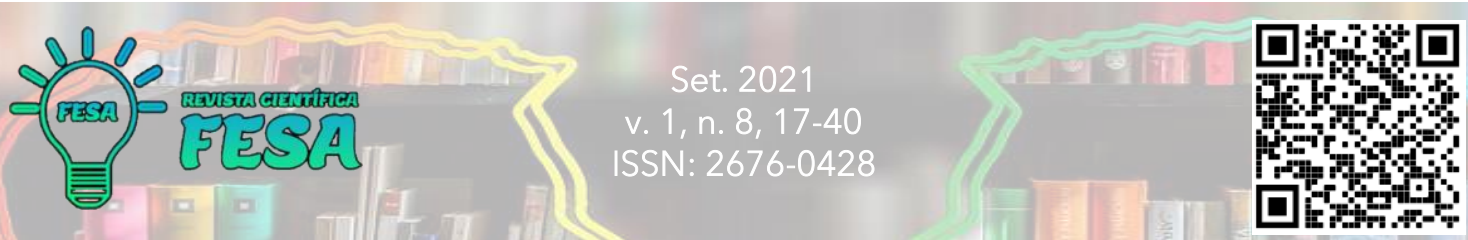

Focalizando a discussão no salvamento terrestre, Nascimento (2017) cita que estão entre as principais atividades de salvamento terrestre o corte de árvore, a desobstrução de via pública, o salvamento veicular, a captura e o extermínio de insetos, a captura e o salvamento de animal, a busca por pessoa desaparecida, a busca e a retirada de cadáver, o salvamento em poço e em fosso, o salvamento de suicida, o resgate de vítima presa em altura, o resgate de vítimas em ambientes confinados, o resgate de vítimas presas em elevadores, dentre outras, que não convém citar, tendo em vista não ocorrerem em número considerável.

Atrelada à preocupação de manter a vítima em segurança, Forlin (2005) cita os vários riscos de acidentes enfrentados pelos profissionais envolvidos em salvamentos tais como os riscos de afogamento, o choque elétrico, o esmagamento, o atropelamento, as lesões perfurocortantes e outras como escoriações, cortes, queimaduras, entorses, luxações e fraturas.

Portanto, entende-se que salvamento é uma operação com o intuito de desenvolver técnicas adequadas a eventos específicos, tais como resgatar vidas humanas, salvamento de patrimônio e animais, prevenir acidentes e recuperações diversas (LUGON, 2016). Assim, as naturezas de ocorrência presentes na atividade de salvamento terrestre estão incluídas as operações de salvamento em elevadores, torres, antenas, edificações, em locais de difícil acesso, em serras e montanhas, salvamento em acidentes automobilísticos e acidentes metroviários, ferroviários, e aéreos além das atividades de corte ou poda de árvore, enxame de insetos, captura de animais, salvamento de animal em risco entre outras naturezas (GTO, 2021).

As práticas de salvamento devem levar em consideração o uso adequado de equipamentos (alavanca "cyborg", almofadas pneumáticas, desencarceradores, serra-sabre, moto-abrasivo, motosserra) e o uso de força coletiva ou multiplicação de força (alavanca, plano inclinado, sarilho, roldana, polia, patesca, moitão, cadernal e talha, vantagem mecânica, sistemas de multiplicação de força).

Dentre as práticas de salvamento, podem-se destacar: contenção mecânica de animais, animais peçonhentos, aranhas e escorpiões; corte de árvore; salvamento veicular; ocorrências com pessoas retidas ou presas em elevador; escoramento de emergência; espaço confinado; movimentação e transporte de vítima em local de difícil acesso; e desabamento. 

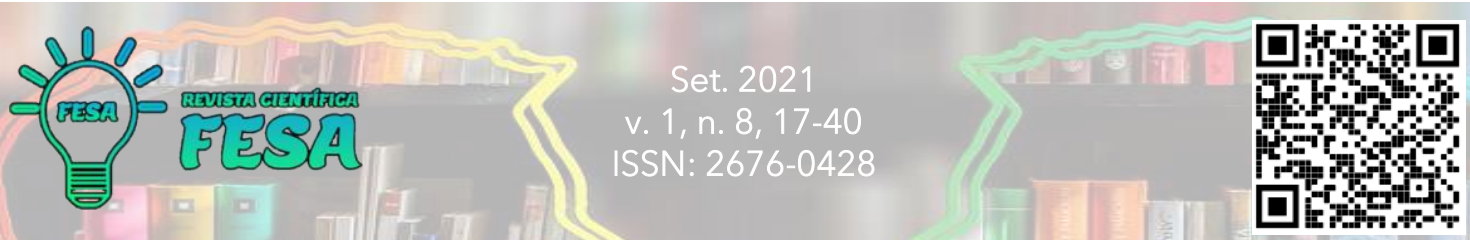

A contenção mecânica de animais, tais como aranhas e escorpiões classificados como peçonhentos, sempre fez parte da rotina humana, havendo registro desses atos até nas pinturas rupestres e nos primeiros registros escritos. Conter um animal significa limitar seus movimentos em diversos graus ou, até mesmo, sua completa imobilização. Dentre esses princípios, ao se lidar com animais domésticos ou silvestres, devem-se reduzir as possibilidades de acidentes, utilizando-se métodos de contenção seguros.

O corte de árvore deve ser realizado dento da lei e por profissionais nas seguintes situações: situações emergenciais caracterizadas pelo risco iminente à vida ou ao patrimônio; situações não emergências para apoio por solicitação de Órgãos públicos; situações não emergenciais por solicitação de particulares (MSTE, 2006).

O salvamento veicular envolve muita técnica da guarnição que deverá trabalhar em equipe, precisando de controle emocional, para atender pessoas com os mais diversos traumas e abaladas emocionalmente, diante de riscos diversos no local do acidente e quando o fator tempo é primordial (MSTE, 2006).

A ocorrências com pessoas retidas ou presas em elevador compreendem situações ocorridas no interior da cabine do elevador, parado por qualquer motivo; ou com "pessoas presas" que compreendem aquelas prensadas entre ferragens ou entre a cabine e a parede (MSTE, 2006).

O escoramento de emergência surge, geralmente, em situações envolvendo soterramento, desabamentos ou risco de desabamentos, (bastante comuns em encostas de morros, canteiros de obras, serviços de manutenção ou instalação de dutos e edificações acometidas por incêndios, explosões ou falha em aspectos construtivos), as guarnições de bombeiro, para garantir sua própria segurança e a segurança das vítimas que estão sendo atendidas (MSTE, 2006).

O espaço confinado é realizado em galerias subterrâneas, uma vez que existem vários tipos de espaços confinados, como por exemplo, poço, valas, reservatórios etc. (MSTE, 2006).

A movimentação e transporte de vítima em local de difícil acesso surge em operações de salvamento terrestre, principalmente aquelas em que os meios de transporte, como viaturas ou aeronaves, não têm acesso a um local próximo onde se localizam as vítimas (MSTE, 2006). 


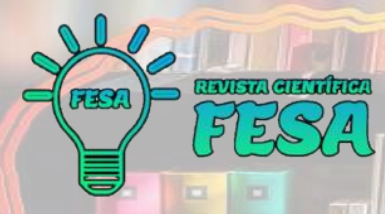

Por fim, os desabamentos ou colapsos estruturais são, geralmente, resultantes da instabilidade do terreno ou do que restou da edificação, cabendo aos profissionais de salvamento a árdua tarefa que é a de executar estratégias e táticas que possibilitem a retirada das vítimas sem, contudo, deixar de lado a segurança deles mesmos (MSTE, 2006).

Com o passar dos tempos e com o avançar da evolução humana, o homem desenvolveu alternativas para os problemas que impediam a sobrevivência, edificando casas, construindo objetos, fabricando roupas e forjando ferramentas. Outro fato de igual destaque é a descoberta do fogo que foi uma das maiores conquistas do homem. Inicialmente, era feito pela queda de raios, porém, com o passar dos tempos, a humanidade aprendeu a provocar o fogo pelo atrito entre as pedras ou madeiras.

Dessa forma, a sobrevivência humana não foi mais a mesma após o controle do fogo, pois os humanos passaram a se proteger do frio, a esquentar os alimentos e a espantar os animais ferozes.

$O$ ato de se manter vivo sempre foi o objetivo maior da humanidade. Assim, as técnicas de sobrevivência reúnem um cabedal de ações emergenciais que devem ser treinadas e aplicadas em casos extremos, permitindo ao sujeito prolongar sua vida e conservar-se fisicamente íntegro até o momento do resgate ou quando se encontre uma saída para os problemas.

O conceito de sobrevivência, de acordo com o dicionário virtual Michaelis (2021) se resume a:

\footnotetext{
1 Ato ou efeito de manter-se vivo, de continuar existindo.; 2 Ação de continuar vivo mais tempo que outra(s) pessoa(s).; 3 Condição de permanecer vivo após acontecimento de gravidade extrema; 4 A continuidade da vida ou existência diante ou a despeito de condições adversas; 5 Aquilo que perdura fora de seu tempo; continuidade, persistência; 6 Manutenção de um estado ou condição; 7 A continuidade da existência após a morte (MICHAELIS, 2021).
}

Podem ser listadas diversas situações extremas de desastres, por exemplo acidentes com meio de transporte, terremotos, naufrágios, que podem colocar a vítima distante da vida civilizada e do socorro. Dessa forma, o conhecimento das técnicas de sobrevivência pode salvar vidas, sendo o treinamento de sobrevivência uma das disciplinas militares de maior destaque. 
O conceito de técnicas de sobrevivência inclui ocorrências extremas com o destaque para a sobrevivência do homem no meio atual proveniente dos avanços científicos, como o uso generalizado de inseticidas e de vacinas, que reduziram as taxas de mortalidade, especialmente infantil e aumento de produção agrícola - o que no mundo atual gerou uma situação em que se permitiu sobreviver - mas não propriamente viver de forma adequada (CASTRO, 2003).

Assim, sobrevivência é um conjunto de conceitos, princípios e técnicas de gestão de riscos que ameaçam a vida que pode contar com o auxílio de recursos materiais facilitadores como bússola, pederneiras e ferramentas de corte.

\section{CUIDADOS COM A SAÚDE}

As primeiras ideias de promoção da saúde foram veiculadas pelos autores Winslow, em 1920, e Sigerist, em 1946, que estabeleceram as quatro tarefas essenciais da medicina: a promoção da saúde; a prevenção das doenças; a recuperação; e a reabilitação.

Sobre isso, o Manual técnico de promoção da saúde e prevenção de riscos e doenças na saúde suplementar desenvolvido pela Agência Nacional de Saúde Suplementar em 2009 define a promoção da saúde:

[...] o significado do termo Promoção da Saúde foi mudando ao longo do tempo e, atualmente, associa-se a valores como: vida, saúde, solidariedade, equidade, democracia, cidadania, desenvolvimento, participação e parceria. Além disso, está relacionado à ideia de "responsabilização múltipla", uma vez que envolve as ações do Estado (políticas públicas saudáveis), dos indivíduos e coletividades (desenvolvimento de habilidades pessoais e coletivas), do sistema de saúde (ANS, 2009, p. 18).

Em seguida, Leavell e Clark, em 1965, elaboraram o modelo da história natural das doenças, que apresenta três níveis de prevenção: primária, secundária e terciária. Portanto, as medidas para a promoção da saúde, em nível de prevenção primário, não são voltadas para determinada doença, mas destinadas a aumentar a saúde e o bem-estar gerais (BUSS, 2003 apud ANS, 2009).

Partindo dos conceitos e das diretrizes de Leavell e Clark (1976) que possuem enfoque centrado no indivíduo, com certa projeção para a família ou grupos, verificou-se sua inadequação para as doenças crônicas não-transmissíveis, 


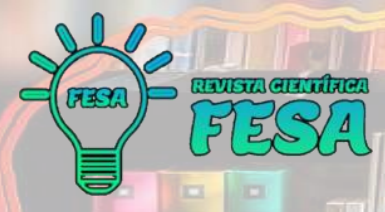

Set. 2021

v. 1, n. $8,17-40$

ISSN: $2676-0428$

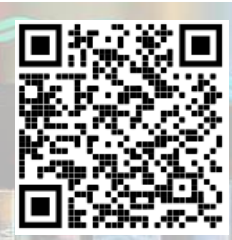

pois a prevenção de tais doenças envolve medidas não só voltadas para os indivíduos e famílias, como também para o ambiente e os estilos de vida (BUSS, 2003 apud ANS, 2009).

Avançando no tempo, o movimento de promoção da saúde surgiu no Canadá, em 1974, por meio da divulgação do documento $A$ new perspective on the health of canadians, também conhecido como Informe Lalonde. A realização desse estudo teve como cenário os custos crescentes da assistência à saúde e o questionamento do modelo centrado no médico no manejo das doenças crônicas, visto que os resultados apresentados eram pouco significativos (BUSS, 2003 apud ANS, 2009).

Em 1986, ocorreu a I Conferência Internacional sobre Promoção da Saúde, que originou a Carta de Ottawa. De acordo com esse documento, "promoção da saúde é o nome dado ao processo de capacitação da comunidade para atuar na melhoria de sua qualidade de vida e saúde, incluindo uma maior participação no controle desse processo. Para atingir um estado de completo bem-estar físico, mental e social (...) Nesse sentido, a saúde é um conceito positivo, que enfatiza os recursos sociais e pessoais, bem como as capacidades físicas. Assim, a promoção da saúde não é responsabilidade exclusiva do setor saúde, e vai para além de um estilo de vida saudável, na direção de um bem-estar global" (CARTA DE OTTAWA, 1986 apud ANS, 2009).

Aumenta, portanto, a anuência de que os aspectos socioculturais, econômicos e ecológicos se investem de uma seriedade tão grande para a saúde quanto os aspectos biológicos, e que saúde e doença são influenciadas pelas condições de vida como um todo. Assuntos como a deterioração do meio ambiente, os modos de vida, as diferenças culturais entre as nações e as classes sociais, e a educação para a saúde passam a estar mais e mais presentes nos debates sobre as formas de se promover a saúde (FARINATTI; FERREIRA, 2006 apud ANS, 2009).

Destarte, Czeresnia (2003 apud ANS, 2009) afirma que as ações preventivas, por sua vez, definem-se como intervenções orientadas a evitar o surgimento de doenças específicas, reduzindo sua incidência e prevalência nas populações. Para tanto, baseiam-se no conhecimento epidemiológico de doenças e de outros agravos específicos. Assim, de acordo com Buss (2003 apud ANS, 2009), a prevenção orienta-se às ações de detecção, controle e enfraquecimento dos fatores 


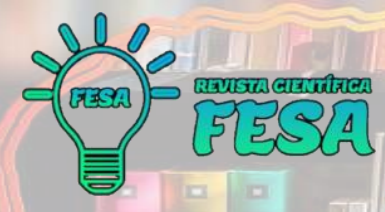

Set. 2021

v. 1, n. $8,17-40$

ISSN: $2676-0428$

de risco de enfermidades, sendo o foco a doença e os mecanismos para atacála.

Divulgado em 2014, o Ministério da Saúde elaborou Os dez passos para uma alimentação saudável que é uma estratégia para buscar uma vida mais saudável, recomendada pelos especialistas em saúde, que deve ser a meta principal de todos os indivíduos que buscam cuidar da saúde e prevenir doenças. Essas orientações podem ser o diferencial na hora que surja a necessidade de colocar o organismo humano à prova. Por exemplo, retomando o caso do piloto que ficou 38 dias perdido na mata, caso uma pessoa que tenha o organismo já enfraquecido por conta de hábitos alimentares pouco contribuitivos, seria mais complicado lidar com tantas intempéries que surgem numa situação assim.

Outra possibilidade de testar a capacidade de resposta do organismo humano é em relação ao resgate que pode demandar tempo e um indivíduo que goze de boa saúde pode ter mais vantagem do que outros. A fim de exemplificação, tem-se o caso da modelo Fernanda Vogel, em 2001, que não resistiu até a chegada do socorro e morreu afogada. Outra modelo que passou por uma situação semelhante foi Caroline Bittencourt, em 2019, que foi arremessada de uma embarcação pelos ventos ao mar e chegou a nadar em busca de ajuda com o marido, mas não aguentou e se afogou. Especulou-se, à época, que as exigências do meio da moda que imputam severas restrições alimentares às modelos poderiam ter influenciado na morte de ambas.

Mesmo não podendo afirmar com certeza que hábitos alimentares mais adequados poderiam fazer a diferença nos episódios anteriores, é importante que todos nós façamos escolhas inteligentes na hora de se alimentar. Dessa forma, faz-se necessário conhecer Os dez passos para uma alimentação saudável:

* 10 passo: Aumente e varie o consumo de frutas, legumes e verduras. Coma-os 5 vezes por dia. As frutas e verduras são ricas em vitaminas, minerais e fibras. Coma, pelo menos, 4 colheres de sopa de vegetais (verduras e legumes) 2 vezes por dia. Coloque os vegetais no prato do almoço e do jantar. Comece com 1 fruta ou 1 fatia de fruta no café da manhã e acrescente mais 1 nos lanches da manhã e da tarde. 


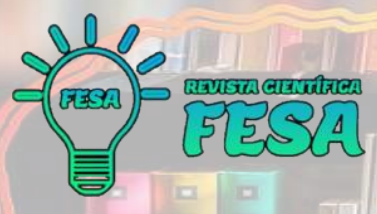

Set. 2021

v. 1, n. 8, 17-40

ISSN: $2676-0428$

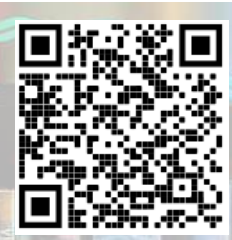

* $\quad 2^{\circ}$ passo: Coma feijão pelo menos 1 vez por dia, no mínimo 4 vezes por semana. O feijão é um alimento rico em ferro. Na hora das refeições, coloque 1 concha de feijão no seu prato, assim você estará evitando a anemia.

* 3ำ passo: Reduza o consumo de alimentos gordurosos, como carne com gordura aparente, salsicha, mortadela, frituras e salgadinhos, para no máximo 1 vez por semana. Retire antes do cozimento a pele do frango, a gordura visível da carne e o couro do peixe. Apesar do óleo vegetal ser um tipo de gordura mais saudável, tudo em excesso faz mal! O ideal é não usar mais que 1 lata de óleo por mês para uma família de 4 pessoas. Prefira os alimentos cozidos ou assados e evite cozinhar com margarina, gordura vegetal ou manteiga.

* 4 passo: Reduza o consumo de sal. Tire o saleiro da mesa. O sal da cozinha é a maior fonte de sódio da nossa alimentação. O sódio é essencial para o funcionamento do nosso corpo, mas o excesso pode levar ao aumento da pressão do sangue, que chamamos de hipertensão. As crianças e os adultos não precisam de mais que 1 pitada de sal por dia. Siga estas dicas: não coloque o saleiro na mesa, assim você evita adicionar o sal na comida pronta. Evite temperos prontos, alimentos enlatados, carnes salgadas e embutidos como mortadela, presunto, linguiça etc. Todos eles têm muito sal.

* 50 passo: Faça pelo menos 3 refeições e 1 lanche por dia. Não pule as refeições. Para lanche e sobremesa prefira frutas. Fazendo todas as refeições, você evita que o estômago fique vazio por muito tempo, diminuindo o risco de ter gastrite e de exagerar na quantidade quando for comer. Evite "beliscar", isso vai ajudar você a controlar o peso.

* 60 passo: Reduza o consumo de doces, bolos, biscoitos e outros alimentos ricos em açúcar para no máximo 2 vezes por semana.

* $\quad 7^{\circ}$ passo: Reduza o consumo de álcool e refrigerantes. Evite o consumo diário. A melhor bebida é a água.

* $\quad$ 8 passo: Aprecie a sua refeição. Coma devagar. Faça das refeições um ponto de encontro da família. Não se alimente assistindo TV.

* 9o passo: Mantenha o seu peso dentro de limites saudáveis - veja no serviço de saúde se o seu IMC está entre 18,5 e 24,9kg/m². O IMC (índice de massa corporal) mostra se o seu peso está adequado para sua altura. É calculado dividindo-se o peso, em kg, pela altura, em metros, elevado ao quadrado. 


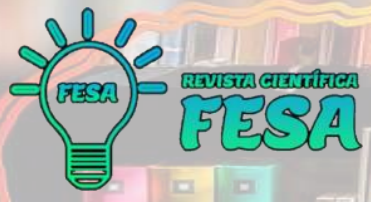

Set. 2021

v. 1, n. $8,17-40$

ISSN: $2676-0428$

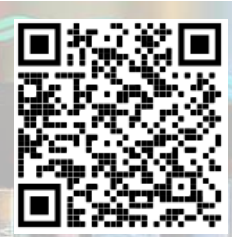

* 10ำ passo: Seja ativo. Acumule 30 minutos de atividade física todos os dias. Caminhe pelo seu bairro. Suba escadas. Não passe muitas horas assistindo TV.

Nota-se, portanto, que essas recomendações foram elaboradas para assegurar aos indivíduos o exercício de hábitos saudáveis e servem como guia para planejar a alimentação de pessoas que precisam de cuidados especiais de saúde, por exemplo. Tais norteadores podem ser utilizados em sujeitos que precisam de dietas especiais, mas devem receber orientações específicas e individualizadas de um nutricionista, de acordo com o seu estado de saúde.

Os aprimoramentos tecnológicos, com a criação dos gadgets, possibilitaram aos indivíduos a adoção de modos de vida mais sedentários, tornando-se mais inativos fisicamente. De igual modo, estudos epidemiológicos demonstram expressiva associação entre estilo de vida ativo, menor possibilidade de morte e melhor qualidade de vida (ACSM, 2007 apud ANS, 2009).

Percebe-se que a atividade física e o exercício previnem, efetivamente, a ocorrência de eventos cardíacos, reduzem a incidência de acidente vascular cerebral, hipertensão, diabetes mellitus do tipo dois, cânceres de cólon e mama, fraturas osteoporóticas, doença vesicular, obesidade, depressão e ansiedade, além de retardarem a mortalidade (ACSM, 2007 apud ANS, 2009).

Assim, pode-se definir a atividade física, de acordo com Capersen et al (1985) como qualquer movimento corporalmente produzido pela musculatura esquelética que resulte em gasto energético (CASPERSEN et al, 1985 apud ANS, 2009). Nahas (2006) acrescenta que a atividade física:

Trata-se de um comportamento humano caracterizado por determinantes de ordem biológica e cultural, igualmente significativos nas escoIhas e nos benefícios derivados desse comportamento (NAHAS, 2006 apud ANS, 2009).

Por sua vez, destaca-se, ainda, que o exercício físico é um tipo de atividade física, definido como o movimento corporal planejado, estruturado e repetitivo realizado com o intuito de melhorar ou manter um ou mais componentes da aptidão física (ACSM, 2007 apud ANS, 2009).

Assim, Carvalho et al (1996 apud ANS, 2009) assevera que, considerando a alta prevalência do sedentarismo aliada ao significativo risco referente às 


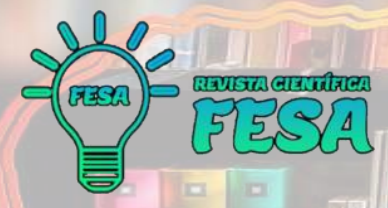

Set. 2021

v. 1, n. 8, 17-40

ISSN: $2676-0428$

doenças crônico-degenerativas, o aumento da atividade física de uma população influencia na qualidade da saúde da coletividade, minimizando custos com tratamentos, inclusive hospitalares, o que reflete seus consideráveis benefícios sociais (CARVALHO et al, 1996 apud ANS, 2009).

\section{SIMBOLOGIA E SINALIZAÇÃO DE SOCORRO}

Ao se procurar uma pessoa ou um grupo que se encontra desaparecido, é necessário que a equipe de resgate esteja atenta aos sinais, ou seja, os símbolos que indicam a localização dos indivíduos que se encontram em situação de sinistro. Geralmente, essas ações envolvem suporte aéreo e terrestre em regiões de mata densa e fechada, sendo indispensável todo e qualquer conhecimento relacionado aos indícios de sobrevivência. Há, ainda, o uso de equipamentos envolvendo a identificação de calor e som que podem ser recursos valiosos para a busca de pessoas que se encontram em situação de perigo. A partir desse ponto, pretende-se listar algumas estratégias que podem servir de suporte para o resgate de vítimas executadas ou pelas equipes ou pelo indivíduo a ser socorrido.

Uma das formas de se colocar em situação de resgate é após a queda de uma aeronave. Embora o índice de letalidade seja alto, é possível sobreviver a uma queda ou a um pouso forçado. Condições climáticas e pane mecânica são motivos recorrentes desses desastres. Geralmente, após uma aterragem forçada, por exemplo, é comum que as vítimas fiquem, desde que possível, por alguns dias junto ao avião, pois sua localização será muito costuma ser mais fácil (PONTES, 1993).

Por outro lado, é comum, também, as vítimas tentarem estabelecer uma comunicação pelo rádio ou ainda preparar sinalizações visuais. O importante é que as ações de resgate sejam executadas o quanto antes a fim de se ampliar as chances de sobrevivência, já que os ferimentos costumam ser graves.

O importante em casos de perigo ou de isolamento é fazer o máximo para ser visto. Quem está perdido precisa tentar estar o mais visível possível e que procura precisa saber procurar. Assim, a equipe de resgate deve ficar atenta a objetos brilhantes ou de coloração viva como a asa do avião, objetos diversos e qualquer aparato que destoe da paisagem. As chapas de carenagem postas com 


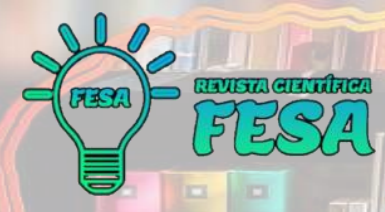

Set. 2021

v. 1, n. 8, 17-40

ISSN: $2676-0428$

o lado sem pintura virado para cima, constituem-se em bons refletores e, por isso, serão mais facilmente visíveis do ar.

Ainda, há objetos cujas cores contrastem com o verde das árvores e do capim, ajudam muito a sua localização inclusive os sinais para improvisação de mensagens no solo (PONTES, 1993).

Uma das formas de se fazer ser visto e de se identificar indícios de vida humana é por meio da visualização de fogo e de fumaça. Além de poder ser visto há muitos metros de distância, esses pontos de fogo ou de fumaça fornecem uma localização precisa e segura.

Então, deve-se observar, com estrema atenção, a existência de fogueiras ou sinais de fumaça, independentemente do tamanho e robustez, pois onde há fogo, geralmente, há vida humana, seja para afugentar animais selvagens, preparar alimentação, manter o aquecimento ou promover algum sinal de sinalização (PONTES, 1993).

Nem sempre, o local de isolamento possibilita a geração de fogo com facilidade, exigindo das vítimas a execução de estratégias que garantam a visualização da localização por meio de outros acelerantes como o combustível, por exemplo.

Dessa forma, por conta do combustível de aeronaves ou da presença de sinalizadores, os sobreviventes costumam utilizar foguetes e as bombas de fumaça para facilitar a localização. Por esse motivo, a equipe de resgate deve estar atenta, e manter uma visão periférica de 360, em busca de qualquer indício de vida ou algum vestígio de sinalização (PONTES, 1993).

Cabe destacar que os artifícios pirotécnicos são fumígenos, geradores de fumaça, que podem ser avistados à distância e fornecer uma localização precisa. Desse modo, elencam-se diversos tipos de fumígenos como aqueles que têm a particularidade de serem luminosos numa extremidade, e na outra, produzir fumaça. Se for durante o dia, em contrapartida, recomenda-se a utilização de fumígenos com uma extremidade com fumaça; se à noite, a luminosa (faísca) (WING ESCOLA, 2021).

Junto ao preparo da equipe de resgate, as pessoas que estão em situação de perigo precisam conhecer algumas estratégias específicas de sinalização para ampliar as chances de regate com vida. Não basta contar com a sorte, 

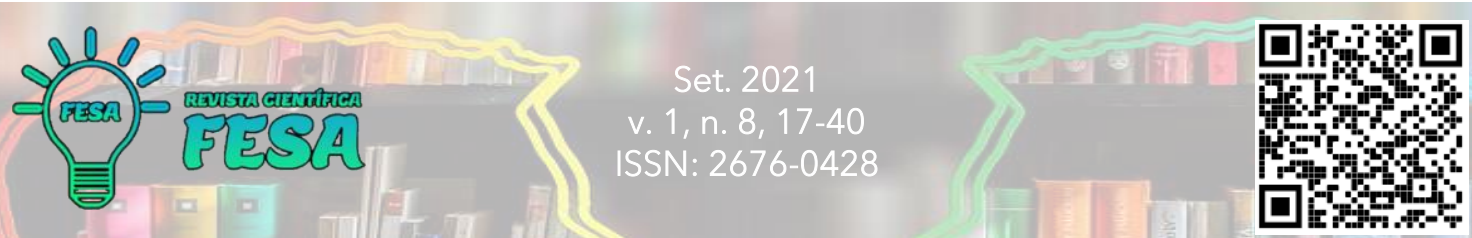

conhecer meios de sinalização em busca de socorro pode ser o diferencial para a sobrevivência (PONTES, 1993).

Será apresentado um rol exemplificativo e não exaustivo, já que as dificuldades encontradas podem fornecer novos meios de localização.

Já foi citada a importância do fogo na sinalização com vistas à localização. Uma das recomendações é a distribuição de diversas fogueiras, num raio de 50 a 100 metros do avião ou do local onde a vítima ou as vítimas se encontram, de maneira que possam ser rapidamente ativadas quando algum barulho de socorro vier a ser percebido durante o dia ou à noite. A fumaça pode ser usada durante o dia, pois não adianta fazer fumaça durante a noite sob o copado fechado, devido a poucas chances de visualização e a fumaça pode ser confundida com nevoeiro. As fumaças nas cores amarelo ou vermelha serão as mais visíveis, mas dependerão da existência de bolsa de sobrevivência e só deverão ser usadas quando se avistar ou ouvir ruído de aeronaves (PONTES, 1993).

A fumaça branca poderá ser obtida de uma fogueira na qual serão lançadas folhas e ramos verdes, limo de árvores ou simplesmente salpicando água. Já a fumaça preta será resultante da queima de óleo, borracha, estopa embebida em óleo, materiais que poderão ser obtidos, se for o caso, no avião acidentado. Próximo a uma dessas fogueiras, mantenha duas latas contendo, respectivamente, óleo de lubrificação e água (PONTES, 1993).

Por fim, a chama, quer das fogueiras, quer a obtida pela queima de material fosfórico, será o recurso para sinalizar durante a noite. Apesar de, normalmente, as buscas se efetuarem a luz do dia, poderão acontecer que qualquer aeronave passe pelo local e observe o sinal (PONTES, 1993).

Outro recurso valioso em momentos de perigo são os espelhos que servem como localizadores e possuem um alcance maior, dependendo do local, do que as fogueiras. Nos dias enevoados, por exemplo, as aeronaves de busca poderão perceber o reflexo do espelho muito antes dos sobreviventes avistarem-nas; para tal, direcione o reflexo do espelho para o lado de onde provém o ruído dos motores, mesmo sem as avistar. O espelho de sinalização tem um alcance de 10 milhas, quando o dia estiver bem claro (WING ESCOLA, 2021).

Desse modo, segure o espelho a poucos centímetros de distância de 10 $\mathrm{cm}$ da face e veja a aeronave através do visor (orifício central). O facho luminoso que passa pelo orifício projetar-se-á na sua face em sua mão ou no seu peito; 
enquanto você mantém em mira a aeronave visada através do visor. Na falta do espelho, improvise com uma lata, fazendo pequeno orifício no centro da tampa em forma de cruz (WING ESCOLA, 2021).

$\mathrm{Na}$ falta de outros meios, poderão ser usados quaisquer objetos que possuam superfície polida (tampa de lata, pedaços da aeronave) que produzam reflexos contra o sol. Serão usados dirigindo-se esses reflexos na direção de onde verão o ruído de motores, mesmo que não se aviste a aeronave e mesmo em dias nublados. Procure se exercitar com o espelho nas horas livres (PONTES, 1993).

Por vezes, os desastres, embora caóticos e de difícil administração, contam com recursos especiais que se destinam a situações de sinistro. Aeronaves, por exemplo, contam com kits voltados para a sobrevivência na mata e no mar e podem ser fundamentais em situações de complexidade. Assim, utilizar essas ferramentas deve seguir protocolos específicos a fim de evitar o desperdício de recursos. Assim, os pós marcadores ou corantes de marcação devem ser usados somente quando avistar ou ouvir uma aeronave. Importante citar, ainda, que estes devem ser utilizados somente durante o dia e demora algum tempo para dissolver e tornar-se visível.

O corante de sinalização, ao ser colocado na água, por exemplo, produz uma mancha verde, que pode ser avistada a longa distância, permanecendo, dependendo da correnteza, por até três horas. Este sinalizador tem um alcance aproximado de 10 milhas, sendo útil em situações de perigo próximo à água (WING ESCOLA, 2021).

Não só os recursos artificiais são úteis, pois recursos naturais devem ser citados de modo importante de igual modo. Muitas vezes, as vítimas não possuem nada além de si mesmos como recursos para se manterem vivos.

Então, se puderem subir em uma árvore alta, procurem arvorar uma bandeira que poderá ser improvisada com pedaço de tecido branco ou de cor viva, amarrando-a a uma vara que deverá ser, por sua vez, amarrada a um galho forte e alto. Isso poderá ser visto pelas equipes de resgate a auxiliar na localização (PONTES, 1993).

O importante é que quem estiver envolvido em uma situação de resgate seja como vítima ou executando a função de salvamento deve estar muito atento aos sinais a fim de ser encontrado ou encontrar alguém. Pequenos detalhes 
podem ser o diferencial nesse momento e a experiência com essas estratégias de sinalização deve fazer parte da formação de todos os seres humanos, já que não há como prever que algo ruim pode acontecer.

\section{ABRIGOS: FORMAS E TIPOS}

Como já informado, a fuselagem de aeronaves pode ser um abrigo ideal em situações de perigo extremo. Entretanto, nem sempre esse recurso está disponível, sendo importante se ter conhecimentos sobre como construir abrigos, utilizando diferentes elementos disponíveis na natureza ou no ambiente como: madeiras, troncos finos e grossos; cipós; cascas de algumas árvores; palhas e folhas de palmeiras e, como já informado, restos da aeronave. Assim, serão descritos alguns abrigos provisórios construídos com folhas diversas.

Em uma sobrevivência na selva é muito importante providenciar abrigos enquanto as equipes de salvamento não localizam e resgatam os sobreviventes. Assim, para montagem de um abrigo provisório, como o rabo de jacu, que é um adequado para passar a noite ou proteção do sol até que se faça outro mais adequado, o sobrevivente deve limpar o local escolhido, procurando juntar boa quantidade de folhas de palmeiras ou de outro tipo, mas que sejam grandes (PONTES, 1993).

Figura 1. Abrigo rabo de jacu de lona de tecido

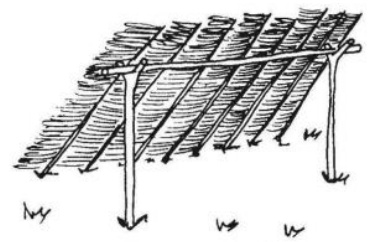

Fonte: Pontes (1993, p. 48)

A seguir, atravesse um pedaço de pau, se possível aproveitando árvores em volta como suporte e vá apoiando as folhas largas, de palmeira ou um pedaço de tecido, se houver, uma ao lado da outra bem unidas. Este é um típico abrigo para uma noite (PONTES, 1993).

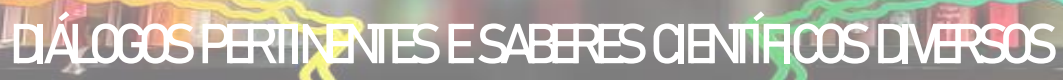


Figura 2. Abrigo rabo de jacu de lona de tecido

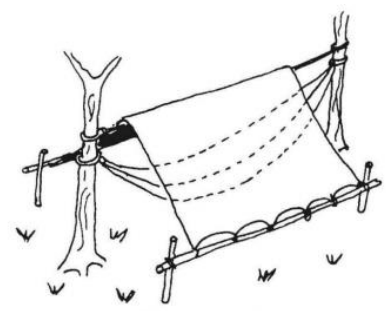

Fonte: Pontes (1993, p. 48)

Decidido o local onde os sobreviventes vão permanecer por mais tempo, deve-se iniciar a construção de um abrigo mais confortável. Assim, orienta-se que se monte uma estrutura em forma de "A", que poderá ser coberta com folhas de palmeiras ou folhas largas que forem possíveis de encontrar (PONTES, 1993).

Figura 3. Abrigo em forma de "A" coberto com folhas largas

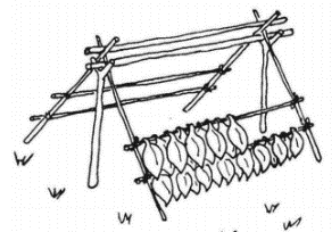

Fonte: Pontes (1993, p. 48)

As folhas deverão ter as pontas para baixo e deverão sobrepor-se como pode ser observado na figura a seguir (PONTES, 1993).

Figura 4. Disposição de folhas

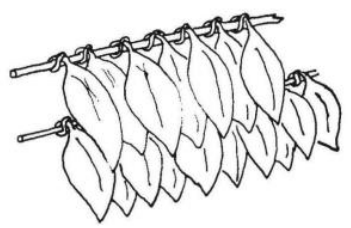

Fonte: Pontes (1993, p. 48)

Dentro deste tipo de abrigo, os sujeitos envolvidos na construção poderão construir uma cama, também chamada de tarimba, de modo acolchoado com o uso de folhas de palmeiras ou vegetação disponível divididas pelo talo, para torná-las mais macias. A figura a seguir ilustra como deve ser feita essa divisão: 
Figura 5. Dividindo talos de palmeira

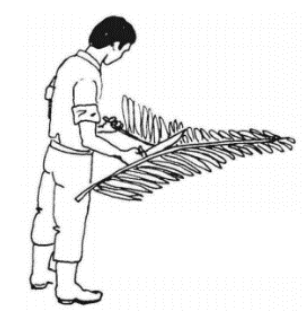

Fonte: Pontes (1993, p. 48)

Para amarração deste tipo de abrigo e da tarimba, use "cipó titica" (cipó de pequeno diâmetro), abundante na floresta. Use-o em seu estado normal ou, caso queira torná-lo mais moldável, tire a casca e divida-o ao meio como pode ser observado na figura anterior. Esse corte nas folhas servirá, também, para fazer vários utensílios para guarda de objetos e inclusive uma armação para transporte de material durante sua caminhada (jamanxim) (PONTES, 1993).

Figura 6. Construção da tarimba

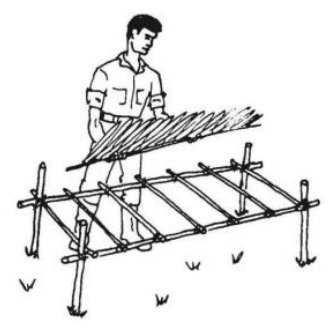

Fonte: Pontes (1993, p. 48)

Se dispuser de pedaços de lona e corda, improvise uma rede no interior do abrigo. Escolha para local do acampamento um ponto elevado, em um pequeno outeiro, o mais possível afastado de charcos e pântanos. Deste modo, os mosquitos incomodarão menos (PONTES, 1993).

Figura 7. Amarração da rede

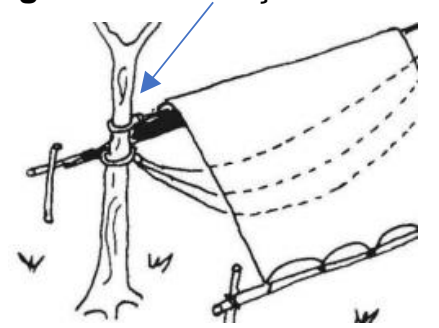

Fonte: Pontes (1993, p. 48) 
Outro tipo de abrigo chama-se rabo de mutum que é feito utilizando dois troncos colocados na vertical e um suporte unindo-os; recobre-se o mesmo com folhas e sob o mesmo amarra-se uma rede (WING ESCOLA, 2021).

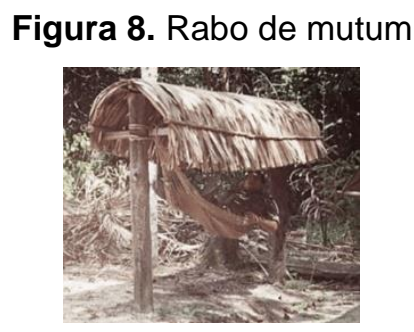

Fonte: Wings Escola.

Outra construção é o tapiri que permite a permanência na selva por um período maior de tempo. Para ser construído, deve-se atentar para as amarrações firmes, com quatro dedos de distância entre os talos das folhas de cobertura e os demais amarrados ao teto; todos os paus do assoalho com o mesmo tamanho. Destaca-se, ainda, que deve haver adequada fixação das estacas, sem pontas irregulares de madeiras e palhas ou folhas (WING ESCOLA, 2021).

Figura 9. Tapiri

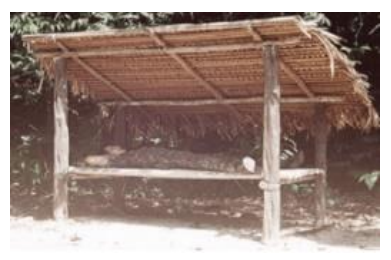

Fonte: Wings Escola.

Nota-se que é necessário construir um abrigo, tipo rabo de jacu ou tapiri, para facilitar a queima próxima de uma fogueira, por exemplo, com cuidado para o armazenamento de material combustível, de alimentos, de roupas, de sinalizadores etc. Outro ponto são as chuvas fortes e inesperadas que podem estragar o que foi guardado. Ainda sobre o fogo, frisa-se que não deve ser construído abaixo do abrigo por conta do risco de incêndio, mas de posicionamento próximo para evitar a perda de calor e inibir a presença de serpentes e animais perigosos (WING ESCOLA, 2021). 


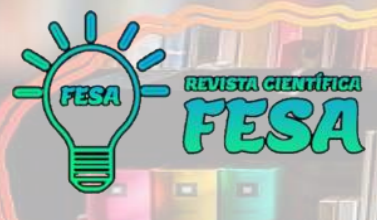

Há, ainda outros tipos de abrigos, como o abrigo japá e o abrigo utilizando poncho que se diferem em complexidade, mas podem ser adequados em determinadas situações.

Figura 10. Abrigo Japá

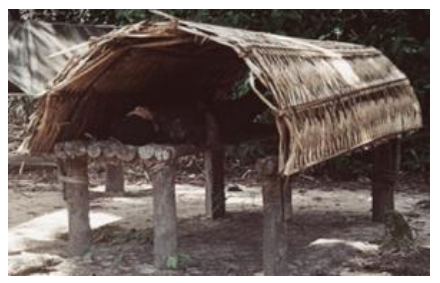

Fonte: Wings Escola.

Esse abrigo se assemelha a um túnel que pode ser improvisado com teIheiro da rede de selva, lonas diversas ou poncho. As canoas, quando disponíveis, podem servir de telhado em situações de selva até o momento de o resgate chegar. Um ponto positivo é que, geralmente, esse abrigo pode ser construído de modo mais elevado do chão, ampliando as possibilidades de conforto por conta da diminuição de insetos e umidade.

Figura 11. Abrigo com poncho

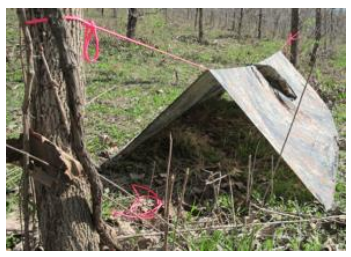

Fonte: Wings Escola.

Sempre que possível, devemos fazer os abrigos para várias pessoas; com isso, os sobreviventes ficam próximos, ocupa-se menos materiais para montagem. Importante frisar que não se deve construir abrigos debaixo de grandes árvores ou embaixo de árvores com galhos secos por conta do risco de desprendimento, já que esses galhos podem cair em cima do abrigo, com resultados imprevisíveis. Outra recomendação é de que não se durma e nem arme abrigo debaixo de castanheiras ou coqueiros, pois as consequências podem ser piores (PONTES, 1993). 


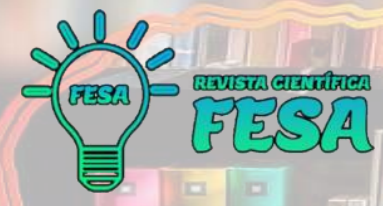

Set. 2021

v. 1, n. $8,17-40$

ISSN: $2676-0428$

Figura 12. Outro tipo de abrigo

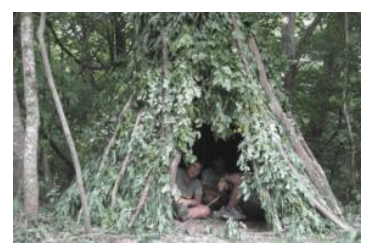

Fonte: Wings Escola.

Por fim, os sobreviventes devem estar atentos ao outro problema comum em situações provisórias: o lixo, que deve ser jogado dentro de uma fossa aberta para este fim, em local afastado do acampamento e da fonte de água. Outro ponto relevante é em relação ao local da latrina que deve ficar o mais possível do acampamento e da água potável. Em caso de impossibilidade, os dejetos deverão ser sempre cobertos com terra de preferência. Portanto, não acampe em terreno de inclinação muito pronunciada ou em área onde houver perigo de avalanches, inundações, queda de rochas, ou em local demasiadamente exposto aos ventos (PONTES, 1993).

\section{CONSIDERAÇÕES FINAIS}

Os conhecimentos teóricos com vistas à execução prática buscaram fornecer subsídios necessários para aprimorar habilidades referentes à sobrevivência e primeiros socorros aos estudantes e futuros profissionais que necessitem desses aprofundamentos para aprimorarem suas práticas laborais pertencentes a diversas áreas do conhecimento.

Assim, cabe destacar que a sobrevivência em plena selva está em íntima ligação com o tempo em que o homem nela permanecer. Para tanto, o homem deverá estar altamente capacitado para dosar suas energias e lançar mão de todos os meios ao seu alcance, a fim de não colocar em risco sua vida. Esta capacidade envolve conhecimentos especializados, invulgares ao homem comum, onde o uso da imaginação, o empenho, o bom senso e o moral elevado, além do instinto de conservação, são fatores preponderantes: encontrar água, alimento e fogo.

\section{REFERÊNCIAS BIBLIOGRÁFICAS}

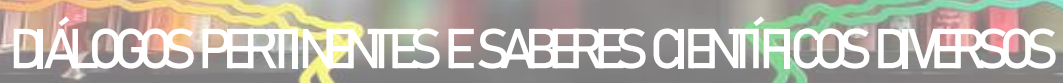



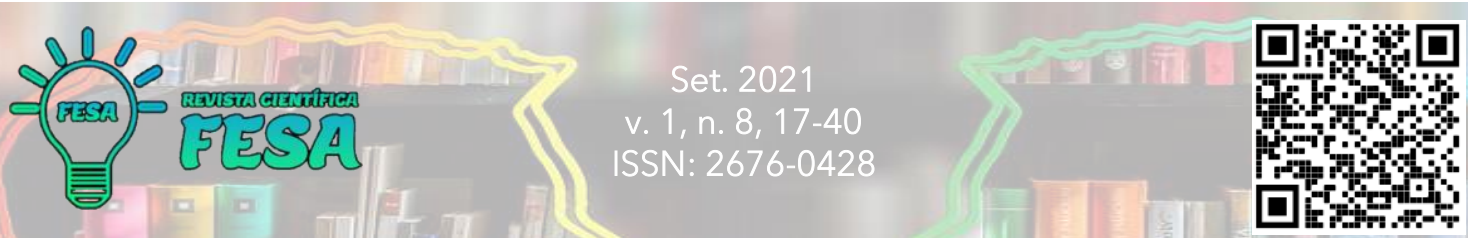

AMERICAN COLLEGE OF SPORTS MEDICINE. Diretrizes do ACSM para o teste de esforço e sua prescrição. 7. ed. Rio de Janeiro: Guanabara Koogan, 2007.

ANS. Agência Nacional de Saúde Suplementar. Manual técnico de promoção da saúde e prevenção de riscos e doenças na saúde suplementar. 3. ed. rev. e atual. - Rio de Janeiro: ANS, 2009.

BUSS, P. M. Uma introdução ao conceito de promoção da saúde. In: CZERESNIA, D.; FREITAS, C. M. (Org.). Promoção da saúde: conceitos, reflexões, tendências. Rio de Janeiro: Ed. Fiocruz, 2003. p. 15-38.

CARVALHO, T. et al. Posição oficial da Sociedade Brasileira de Medicina do Esporte: atividade física e saúde. Revista Brasileira de Medicina do Esporte, v. 2, n. 4, p. 79-81, 1996.

CASPERSEN, C. J.; POWEL, K. E.; CHRISTENSON, G. M. Physical activity, exercise, and physical fitness: definitions and distinctions for health-related research. Public Health Reports, v. 100, n. 2, p. 126-131, 1985.

CASTRO, Josué de. Fome, um tema proibido: últimos escritos de Josué de Castro. Editora Record: São Paulo, 2003.

CBESC. Corpo de Bombeiros do Estado de Santa Catarina. Portal Institucional. Disponível em: https://www.cbm.sc.gov.br/index.php/institucional/o-cbmsc. Aceso em: 31 mai. 2021.

CONFERÊNCIA INTERNACIONAL SOBRE PROMOÇÃO DA SAÚDE. 1., 1986, Ottawa. Carta de Ottawa. Ottawa, 1986.

CZERESNIA, D. O conceito de saúde e a diferença entre prevenção e promoção. In: CZERESNIA, D.; FREITAS, C. M. (Org.). Promoção da saúde: conceitos, reflexões, tendências. Rio de Janeiro: Ed. Fiocruz, 2003. p. 39-53.

GAZETA. Gata presa em telhado mobiliza resgate dos Bombeiros em Vitória. Disponível em: https://www.agazeta.com.br/es/cotidiano/gata-presa-em-telhado-mobiliza-resgate-dos-bombeiros-em-vitoria-veja-video-0521 Acesso em: 31 mai. 2021.

GTO. Grupo Temático Operacional. Salvamento Terrestre. 2021. Disponível em: https://gto.bombeiros.mg.gov.br/salvamento-terrestre Acesso em: 31 mai. 2021.

FARINATTI, P. T. V.; FERREIRA, M. S. Saúde, promoção da saúde e educação física: conceitos, princípios e aplicações. Rio de Janeiro: Ed. UERJ, 2006.

LEAVELL, H. R.; CLARK, E. G. Medicina preventiva. São Paulo: McGraw Hill do Brasil, 1976.

LUGON, André Pimentel. Curso de Formação de Brigadistas Profissionais. Salvamento terrestre. CBMES. Corpo de Bombeiros Militar do Espírito Santo, 

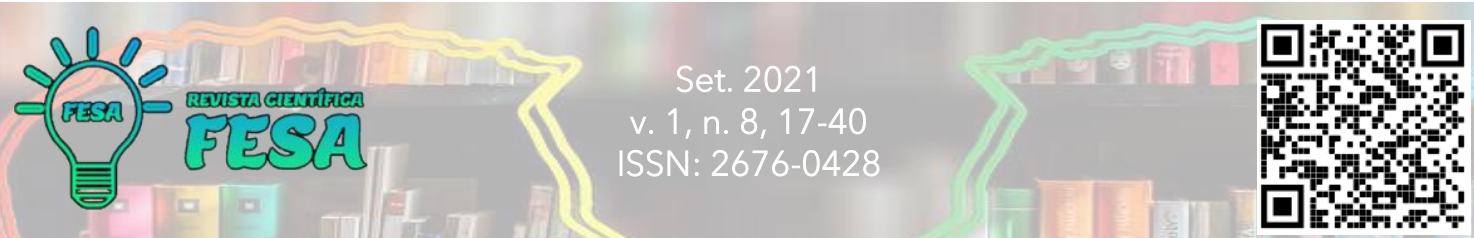

2016. Disponível em: https://cb.es.gov.br/Media/CBMES/PDF's/CEIB/SCE/Material\%20Didatico/CFBP-SALVAMEN TO\%20TERRESTRE\%20-\%202016.pdf Acesso em: 31 mai. 2021.

MICHAELIS. Dicionário Brasileiro da Língua Portuguesa. Salvamento. Disponível em: https://michaelis.uol.com.br/busca? $r=0 \& f=0 \& t=0 \&$ palavra=salvamento Acesso em: 31 mai. 2021.

MICHAELIS. Dicionário Brasileiro da Língua Portuguesa. Sobrevivência. Disponível em:

https://michaelis.uol.com.br/moderno-portugues/busca/portugues-brasileiro/sobrevi v\%C3 \%AAncia/ Acesso em: 31 mai. 2021.

MSTE. Manual de Salvamento Terrestre. Coletânea de Manuais Técnicos de Bombeiros. Disponível em: https://www.bombeiros.com.br/imagens/manuais/manual-03.pdf Acesso em 31 mai. 2021.

NAHAS, M. V. Atividade física, saúde e qualidade de vida: conceitos e sugestões para um estilo de vida ativo. 4. ed. rev. e atual. Londrina: Midiograf, 2006.

NASCIMENTO, Marcos Guedes do. Proposição de medidas de segurança para redução dos riscos de acidentes existentes na atividade operacional de corte de árvore do batalhão de busca e salvamento do Corpo de Bombeiros Militar da Paraíba. Disponível em: https://periodicos.unipe.br/index.php/interscientia/article/view/483/487 Acesso em: 31 mai. 2021.

PARANÁ RPC. Homem é resgatado com ferimentos após cair de paredão no Morro do Anhangava. Aventuras na História, 2021. Disponível em https://g1.globo.com/pr/parana/noticia/2021/0 5/16/homem-e-resgatado-com-ferimentos-no-morro-do-anhangava-apos-queda-de-pareda o-diz-policia.ghtml Acesso em: 31 mai. 2021.

PONTES, Cícero Feliciano. Manual de sobrevivência na Selva. IBGE: Rio de Janeiro, 1993.

FORLIN, M.A.S. Riscos Profissionais. Porto Alegre: Polost, 2005.

SOBRASA.ORG. A atividade de salvamento aquático em Santa Catarina: atuação em conjunto dos salva-vidas militares com os salva vidas civis. Disponível em: http://www.sobrasa.org/campeonato/simposio_temas/salva_vidas_civil_sc.pdf> Acesso em: 31 mai. 2021.

UOL. Piloto é encontrado em floresta no Pará após 38 dias desaparecido, 2021. Disponível em: https://aventurasnahistoria.uol.com.br/noticias/historiahoje/piloto-e-encontrado-em-floresta-no-para-apos-38-dias-desaparecido.phtml Acesso em 31 mai. 2021.

WING ESCOLA. SOS Sobrevivência da Selva: Sinalizações. Wings: 2017. Disponível em: https://wingsescola.com.br/sobrevivencia-na-selva-sinalizacoes/ Acesso em 02 jun. 2021. 